\title{
Molecular ecology meets remote sensing: environmental drivers to population structure of humpback dolphins in the Western Indian Ocean
}

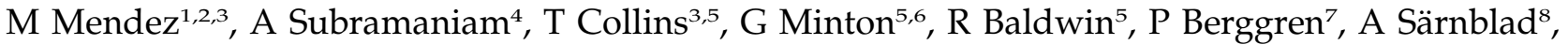 \\ OA Amir ${ }^{9}$, VM Peddemors ${ }^{10,11}$, L Karczmarski ${ }^{12}$, A Guissamulo ${ }^{13}$ and HC Rosenbaum ${ }^{1,3}$ \\ ${ }^{1}$ Sackler Institute for Comparative Genomics, American Museum of Natural History, New York, NY, USA; ${ }^{2}$ Department of Ecology, \\ Evolution and Environmental Biology, Columbia University, New York, NY, USA; ${ }^{3}$ Ocean Giants Program, Wildlife Conservation \\ Society, Bronx, NY, USA; ${ }^{4}$ Lamont Doherty Earth Observatory, Columbia University, Palisades, NY, USA; ${ }^{5}$ Environment Society of \\ Oman, Al-Khuwair, Muscat, Sultanate of Oman; ' ${ }^{6}$ Sarawak Dolphin Project, Institute of Biodiversity and Environmental Conservation, \\ University Malaysia Sarawak, Kota Samarahan, Sarawak, Malaysia; ${ }^{7}$ School of Marine Science and Technology, Newcastle University, \\ Newcastle upon Tyne, UK; ${ }^{8}$ Department of Zoology, Stockholm University, Stockholm, Sweden; ${ }^{9}$ Institute of Marine Sciences, University \\ of Dar es Salaam, Zanzibar, Tanzania; ${ }^{10}$ School of Biological and Conservation Sciences, University of KwaZulu-Natal, Durban, South \\ Africa; ${ }^{11}$ Cronulla Fisheries Reseach Centre, Cronulla, New South Wales, Australia; ${ }^{12}$ The Swire Institute of Marine Science, School of \\ Biological Sciences, The University of Hong Kong, Cape d'Aguilar, Shek O, Hong Kong and ${ }^{13}$ Universidade Eduardo Mondlane, Museu \\ de História Natural, Praça Travessia do Zambeze, Maputo, Mozambique
}

Genetic analyses of population structure can be placed in explicit environmental contexts if appropriate environmental data are available. Here, we use high-coverage and highresolution oceanographic and genetic sequence data to assess population structure patterns and their potential environmental influences for humpback dolphins in the Western Indian Ocean. We analyzed mitochondrial DNA data from 94 dolphins from the coasts of South Africa, Mozambique, Tanzania and Oman, employing frequencybased and maximum-likelihood algorithms to assess population structure and migration patterns. The genetic data were combined with 13 years of remote sensing oceanographic data of variables known to influence cetacean dispersal and population structure. Our analyses show strong and highly significant genetic structure between all putative populations, except for those in South Africa and Mozambique. Interestingly, the oceanographic data display marked environmental heterogeneity between all sampling areas and a degree of overlap between South Africa and Mozambique. Our combined analyses therefore suggest the occurrence of genetically isolated populations of humpback dolphins in areas that are environmentally distinct. This study highlights the utility of molecular tools in combination with highresolution and high-coverage environmental data to address questions not only pertaining to genetic population structure, but also to relevant ecological processes in marine species. Heredity (2011) 107, 349-361; doi:10.1038/hdy.2011.21; published online 23 March 2011

Keywords: population structure; remote sensing; environmental drivers

\section{Introduction}

Population structure in cetaceans and other mobile marine species has been widely documented worldwide (Mendez et al., 2008, 2010; Rosenbaum et al., 2009; Andrews et al., 2010), and the availability of highresolution molecular tools has significantly increased our understanding of this phenomenon (DeSalle and Amato, 2004; Waples and Gaggiotti, 2006). However, the general scarcity of environmental data in these types of studies has largely precluded evaluating the influence of presumably important environmental variables in

Correspondence: $\operatorname{Dr}$ M Mendez, Sackler Institute for Comparative Genomics, American Museum of Natural History, Central Park West at 79th Street, New York, NY 10024, USA.

E-mail:mmendez@amnh.org

Received 4 October 2010; revised 10 January 2011; accepted 10

February 2011; published online 23 March 2011 marine dispersal and population structure. Remote sensing can offer broad-scale and high-resolution environmental data to match the spatial scale of regional and local genetic analyses. A variety of satellite sensors currently provides freely available comprehensive oceanographic data, including retrospective data, which allows integrating environmental and genetic information for marine species.

The combination of multiple lines of evidence for marine dispersal might allow a transition from studies describing the spatial genetic patterns of the species of interest, to evaluations of the influence of spatially explicit environmental variables on genetic structure. Accounts of genetic structure in relation to the spatial arrangement of putative populations or sampling units have typically been related to the presence or absence of 'isolation by distance' (IBD), a mechanism postulating that the genetic distance between populations is correlated to their geographic separation (Wright, 1943; 
Krützen et al., 2004). Recent studies that include spatially explicit oceanographic information are beginning to show hints of overlap between oceanographic and genetic discontinuities that complement the IBD evidence (that is, Fullard et al., 2000; Gaggiotti et al., 2009; Mendez et al., 2010). Moreover, it has been shown that cetacean population structure may not only be spatially coincident with oceanographic boundaries, but that the magnitudes of both discontinuities are sometimes correlated. This led to the postulation of a mechanism of 'isolation by environmental distance' (IBED), in which the environmental distance between populations correlates with their genetic separation (Mendez et al., 2010).

In this paper, we evaluate the extent to which marine features and habitat heterogeneity can explain the genetic patterns of population structure of a cetacean species. To tackle this question, we first inspect environmental data to assess heterogeneity in the study area and evaluate whether such environmental discontinuities coincide with the observed genetic breaks between populations. Second, we evaluate whether either or both IBD or IBED adequately describe the type of relationships between environmental and genetic structure. Although, theoretically, all three mechanisms (environmental breaks, IBD and IBED) could independently or simultaneously explain the genetic data, it has been shown that appropriate testing frameworks can help decouple their interaction (Mendez et al., 2010).

Our choice of the environmental variables for this evaluation is related to previous genetic-environmental assessments involving cetaceans (Fullard et al., 2000; Mendez et al., 2010), which suggested that chlorophyll concentration (CHL or chlorophyll), water turbidity and sea-surface temperature can explain, at least partially, observed genetic patterns. In addition, upwelling areas, ocean currents, depth and slope have been identified as important factors influencing the distribution and abundance of cetaceans, and may presumably influence dispersal and population structure (Davis et al., 2002).

We test the above mentioned issues of population structure in relation to environmental heterogeneity in the Indo-Pacific humpback dolphin (Sousa chinensis), which is distributed in the coastal waters of the Indian Ocean basin from South Africa to China and along the coasts of Australia (Karczmarski et al., 1999a; Jefferson and Karczmarski, 2001; Atkins et al., 2004; Hung and Jefferson, 2004; Parra et al., 2004; Sutaria and Jefferson, 2004; Wang et al., 2004; Amir et al., 2005). The taxonomy of the genus is largely unresolved and there are presently two recognized species, the Indo-Pacific and Atlantic (Sousa teuszii) humpback dolphins (Jefferson and Karczmarski, 2001). However, some taxonomists propose an additional partition of the Indo-Pacific species into western Indo-Pacific (Sousa plumbea) and eastern IndoPacific (S. chinensis) (Rice, 1998; Frere et al., 2008).

Humpback dolphins inhabit the warm and shallow waters of the continental shelf, typically up to depths of $25 \mathrm{~m}$, and are frequently seen in the proximity of rivers, deltas and estuaries (Karczmarski et al., 2000; Atkins et al., 2004; Stensland et al., 2006). They usually form small groups ranging between 2 and 13 individuals along the eastern African coastline (Karczmarski, 1999; Peddemors, 1999; Stensland et al., 2006), although larger group sizes have been frequently recorded around the Arabian Peninsula, and in particular along the Arabian
Sea coast of Oman (Baldwin et al., 2004). Photographic and observational data suggest significant emigration and immigration from sampling areas in South Africa (Karczmarski et al., 1999a, 1999b; Keith et al., 2002) and Mozambique (Guissamulo and Cockcroft, 2004), and patterns of residency in Tanzania (Stensland et al., 2006). Related evidence implies that humpback dolphins are capable of traveling distances of at least $150 \mathrm{~km}$ (Karczmarski et al., 1999a, b; Keith et al., 2002).

Humpback dolphins display habitat preferences and demographic parameters that seem associated with distinct environmental features, making this species ideal for the current study. In the southern portion of their range, they are typically observed feeding in shallow rocky reefs (Karczmarski et al., 1999b), but further north are inevitably closely associated with areas where fresh and salt water mix (Peddemors and Thompson, 1994; Parsons, 1998; Karczmarski et al., 1999b; Atkins et al., 2004). Around the Arabian Peninsula, humpback dolphins are mostly seen associated with shallow waters and sandy and vegetated substrates (Baldwin et al., 2004). The diurnal behavior of humpback dolphins shows variations associated with changes in sea-surface temperature (Parsons, 2004) and diurnal cycles of their prey (Karczmarski, 1999; Karczmarski and Cockcroft, 1999). In addition, seasonal variation in population size has been attributed to differences in surface temperature and salinity, and to significant differences in prey abundance (Karczmarski et al., 1999a, b; Guissamulo and Cockcroft, 2004; Parsons, 2004).

Indo-Pacific humpback dolphins are listed as 'near threatened' by the IUCN and are listed in Appendix I of CITES, mainly as a consequence of fisheries interactions, habitat disruption and habitat loss (Reeves et al., 2008). Although analyses of population structure are considered fundamental elements of conservation and management strategies (DeSalle and Amato, 2004), virtually no such analyses have been conducted for the species (but see Jefferson and Hung (2004) for an exception).

In this study, we combine mitochondrial DNA (mtDNA) data with environmental information to investigate the influence of a suite of oceanographic variables on cetacean population genetic structure. Overall, we seek to increase our understanding of marine dispersal and consider new elements for conservation strategies involving mobile marine species.

\section{Materials and methods}

\section{Sample collection and DNA sequencing}

Tissue samples of 94 individuals were obtained from incidentally entangled, beach-cast and biopsied humpback dolphins along their distribution range in the Western Indian Ocean, between South Africa and Oman. All samples were preserved in ethanol $(96 \% \mathrm{v} / \mathrm{v})$ or in sodium chloride-saturated $20 \%$ dimethyl sulphoxide solution. In all, 20 samples were collected in South Africa, 5 in Mozambique, 11 in Tanzania, 58 in Oman and 2 in Madagascar. The samples collected in Madagascar were excluded from all analyses, excepting the construction of haplotype networks, due to their small number (see below). Although the Mozambique and Tanzania samples are relatively small, the samples used in this 
analysis are the only ones that exist for the study area and can therefore provide relevant population structure information. Moreover, these sample sizes are comparable to those used in other population genetic studies in cetaceans (Dalebout et al., 2001; Chivers et al., 2002; Rosa et al., 2005; Mendez et al., 2010).

Total genomic DNA was extracted from tissue samples using the QIAamp Tissue Kit (QiaGen, Valencia, CA, USA). A fragment of $457 \mathrm{bp}$ of the mtDNA control region was amplified (primers dlp1.5 and dlp5) (Baker et al., 1993), and sequenced in both directions using a 3730xl DNA Analyzer (Applied Biosystems, Inc., Foster City, CA, USA).

Matching of sequences to haplotypes was completed using COLLAPSE v1.2 (available from http://darwin. uvigo.es) and DnaSP v5.0 (Rozas et al., 2003). Haplotype diversity, $H_{d}$, (Nei, 1987), the mean number of pairwise differences among sequences, $k$ (Tajima, 1983), and the nucleotide diversity, $\pi$ (Nei, 1987) in our sample were assessed using Arlequin v3.1 (Excoffier et al., 2005) and DnaSP.

\section{Analysis of population structure}

We used mtDNA sequence data to test for population structure between four sampling locations along the Western Indian Ocean, where humpback dolphins are reported as bycatch: South Africa, Mozambique, Tanzania and Oman. Spatial structure of the mtDNA data set among the putative populations was evaluated through the analysis of molecular variance in Arlequin. Pairwise $F_{\text {ST }}$ (haplotype frequencies only) and $\Phi_{\mathrm{ST}}$ statistics (pairwise differences between haplotypes) were computed, and their significance tested, using the null distribution generated from 10000 non-parametric random permutations of the data. No corrections for multiple tests were made (Perneger, 1998; Narum, 2006). The extent of geographical heterogeneity in haplotype frequency distributions was further assessed through a $\chi^{2}$-test, conducted in DnaSP, and an Exact-test implemented in Arlequin. Patterns of genetic variation between the identified haplotypes were depicted using median joining networks (Bandelt et al., 1999) as implemented in Network (http://www.fluxus-engineering. com), and were compared with statistical parsimony networks (Clement et al., 2000).

In addition to the general patterns of population structure, we were particularly interested in genetic patterns between contiguous putative populations. Like Franciscana dolphins (Pontoporia blainvillei) and other obligate shallow water dolphins (Mendez et al., 2008, 2010), humpback dolphins display a coastal distribution pattern, suggesting that these animals are most likely to move along the coast through adjacent strata. Therefore, comparisons of adjacent strata (that is, South AfricaMozambique, Mozambique-Tanzania, Tanzania-Oman) would be biologically more meaningful than any other pairwise comparisons.

To complement our genetic distance estimations between adjacent populations, we estimated migration rates using maximum likelihood and Bayesian procedures implemented in the MDIV software (Nielsen and Wakeley, 2001) and in MIGRATE (Beerli and Felsenstein, 2001). Our rationale was to use MDIV to assess relative differences of symmetric migration rates between adjacent strata and complement those estimations with an evaluation of asymmetric migration rates, implemented in MIGRATE. MDIV simultaneously estimates the migration rate per gene per generation between populations scaled by the effective population size $\left(M=2 N_{\mathrm{e}} m\right)$, the divergence time scaled by the effective population size $\left(T=t / 2 N_{\mathrm{e}}\right)$, and the parameter theta $\left(\theta=4 N_{\mathrm{e}} \mu\right)$. Markov chains of $10^{7}$ cycles were run with $10^{5}$ cycles of burn-in to minimize dependence on initial conditions. The model values for $\theta$ and $T_{\max }$ (maximum value for the scaled divergence time) were $\theta=0$ and $T_{\max }=5$. The choice of $\theta=0$ provided the model with a flat previous hypothesis, which had the least influence on the parameter estimation. A $T_{\max }=5$ and a comparisondependent $M_{\max }$ (maximum value for the scaled migration rate) were well above the estimated $T$ and $M$ in our sensitivity analysis, ensuring that our model contained all possible $T$ and $M$ values. In all, 10 converged runs for each population comparison were used to identify $M, T$ and $\theta$ values corresponding to the maximum likelihood. MIGRATE provides estimates of $M(\mathrm{~m} / \mu)$ and $\theta(2 \mathrm{Ne} \mu)$, where $\mathrm{m}$ is the immigration rate, $\mu$ the mutation rate, and Ne the effective population size. The product $\theta M$ results in the number of immigrants per generation $2 \mathrm{~N}_{\mathrm{e}} \mathrm{m}$. We adopted a migration matrix model allowing for asymmetric migration rates between regions and variable subpopulation sizes. The following Markov chain scheme was implemented: 20 short chains (dememorization: 10000 genealogies, recorded genealogies: 2500, sampling increment: 100) and 3 long chains (dememorization: 10000 genealogies, recorded genealogies: 25000 , sampling increment: 100).

\section{Analysis of environmental structure}

Our study area is encompassed in the Coastal Biome (sensu Longhurst, 2006), which is defined between the coastline and the outer limit of the continental platform at all latitudes excepting the polar regions.

The northern portion of our study area is delimited by the Arabian Sea Upwelling Province, extending from central Kenya to Pakistan (Longhurst, 2006). A narrow shelf characterizes most of the province, with the exception of some parts of Oman, where the shelf can extend $75 \mathrm{~km}$ from shore. A salient climatic feature of this province is the annual monsoon, which drives a reversal of the Somali coastal current and the occurrence of upwelling areas off Somalia, Yemen and southern Oman (Longhurst, 2006). A permanent feature throughout the year, the South Equatorial Current meets the African continent at approximately $10^{\circ} \mathrm{S}$, and then diverges north into the African Coastal Current and south into the Mozambique Channel. At the start of the boreal winter (late December or early January), the Northeast Monsoon causes southward flow on the western margin of the Arabian Sea, particularly from northern Somalia $\left(10^{\circ} \mathrm{N}\right)$ to central Kenya $\left(2-3^{\circ} \mathrm{S}\right)$. This southern flow meets the northern flow of the East African Coastal Current, and both diverge offshore into the South Equatorial Counter Current at approximately $5^{\circ} \mathrm{S}$. With the onset of the boreal summer (late June or early July), the Southwest Monsoon reinforces the East African Coastal Current and increases the northeast flow of the Somali current, reversing the situation observed in the boreal winter. In this case, the northeastern current 
reaches the head of the Arabian Sea into the Indian subcontinent. The monsoon causes a series of surges, which induce upwelling along the Somali coast and northwards into Yemen and southern Oman (Longhurst, 2006).

The southern portion of the study area is within the Eastern African Coastal Province, which extends from central Tanzania $\left(5^{\circ} \mathrm{S}\right)$ to the Cape of Good Hope in South Africa (Longhurst, 2006). The shelf in this area is also relatively narrow with a steep slope, although there are several examples of broader shelf areas in the region; for instance, the area between 4 and $7^{\circ} \mathrm{S}$ in central Tanzania, where there are extensive reefs that support shallow coral communities, the coast of Mozambique and east Madagascar, with the shelf break between $100 \mathrm{~km}$ and $150 \mathrm{~km}$ offshore, and the Agulhas Bank in southern South Africa, with the shelf break at about $180 \mathrm{~km}$ offshore. Several large rivers drain onto the shelf in this province, including the Zambezi ( $18^{\circ} \mathrm{S}$ approximately) and Limpopo rivers ( $25^{\circ} \mathrm{S}$ approximately). The generally southbound flow along the African coast of the Mozambique Channel is influenced by a series of gyres, which often cause inshore countercurrents (Longhurst, 2006). The southern end of the Mozambique Channel is the origin of the Agulhas current, which flows south and widens southward (Lutjeharms et al., 2000).

To complement the oceanographic characterization of this region summarized by Longhurst (2006), we collected empirical data for some of the oceanographic variables previously related to habitat heterogeneity. Specifically, we gathered satellite-derived spatially explicit data on surface currents, CHL, color-dissolved organic matter (or dissolved matter), diffused attenuation coefficient at $490 \mathrm{~nm}$, a measure of water turbidity (K490 or turbidity), and surface temperature, as these are available with wide coverage through remote sensing. Further information on the satellite-derived data is presented in Table 1 . In order to empirically assess regional environmental heterogeneity, we constructed surface-current maps representing each of the four seasons and built bathymetry, average and standarddeviation chlorophyll, dissolved matter, turbidity and temperature maps for the entire region between 1997 and 2010, using the SeaDAS software (oceancolor.gsfc. nasa.gov) and the OSCAR's data-display platform. To evaluate whether the sampling areas are environmentally distinct, we extracted time series of chlorophyll, dissolved matter, turbidity and temperature data for the estimated sampling polygons in each of the sampled countries. In South Africa, the sampling polygon was defined between $23^{\circ} \mathrm{E}, 27^{\circ} \mathrm{E}, 35^{\circ} \mathrm{S}$, and the coastline. In Mozambique, the polygon boundaries were $24^{\circ} \mathrm{S}, 27^{\circ} \mathrm{S}$, $36^{\circ} \mathrm{E}$, and the coastline. In Tanzania, the sampling polygon was defined between $5^{\circ} \mathrm{S}, 7^{\circ} \mathrm{S}, 42^{\circ} \mathrm{E}$, and the coastline. In Oman, the sea portion of the polygon was between $22^{\circ} \mathrm{N}, 18^{\circ} \mathrm{N}, 61^{\circ} \mathrm{E}$, and $57^{\circ} \mathrm{E}$, to include those areas where Humpback dolphin specimens were collected. The time-series data were obtained for each of these four polygons at a one-month resolution (that is, each point in these time-series is a 30-day average), from September 1997 to February 2010 for chlorophyll, dissolved matter, and turbidity, and from September 2002 to February 2010 for temperature.

We empirically evaluated environmental differences between the sampling areas qualitatively and quantitatively. First, we inspected the regional maps of bathymetry, currents, chlorophyll, dissolved matter, turbidity and temperature to identify spatial structure in the data, and geographical areas of high environmental heterogeneity. Second, in order to compare contiguous humpback dolphin sampling areas (polygons), we averaged the monthly time series and assessed differences between the means with a paired $t$-test, accounting for the spatial dependence between contiguous sampling sites. Third, we used the monthly time-series data to build climatologies (that is, an annual series composed of 12 monthly averages calculated from the entire timeseries data set) for each of the four variables at the sampling polygons, and quantitatively compared these climatologies through observation of the mean and standard error values in the series.

\section{Joint genetic and environmental analyses}

To evaluate whether genetic discontinuities (or breaks) between populations could be influenced by environmental heterogeneity, we first assessed whether there were contiguous populations that were genetically differentiated, and for which the environmental data showed significant discontinuities.

Second, in order to evaluate whether IBD could explain the genetic patterns in the study area, we tested for potential correlations between the pairwise genetic $\left(F_{\mathrm{ST}}\right)$ and geographical distances $(\mathrm{Km})$ using Mantel tests with 10000 random permutations of the data matrices in IBD v3.16 (Bohonak, 2002). Geographical distances were calculated as the linear distance between the approximate centroid of the area where animals were sampled along the coastline using Arc GIS (Environmental Systems Research Institute, Inc., Redlands, CA, USA). Rejection of the null hypothesis of a negative or flat slope for the correlation between variables is used as evidence of IBD.

Last, in order to evaluate whether IBED could explain the genetic patterns in the study area, we tested for correlations between the pairwise genetic and

Table 1 Remote sensing data sources

\begin{tabular}{lllll}
\hline Variable & Sensor/source & Spatial resolution & Temporal resolution & Website \\
\hline CHL & SeaWiFS & $9 \mathrm{~km}$ & 8-day & oceancolor.gsfc.nasa.gov \\
CDOM & SeaWiFS & $9 \mathrm{~km}$ & 8-day & oceancolor.gsfc.nasa.gov \\
K490 & SeaWiFS & $9 \mathrm{~km}$ & 8-day & oceancolor.gsfc.nasa.gov \\
SST & TerraMODIS & $4 \mathrm{~km}$ & 8-day & oceancolor.gsfc.nasa.gov \\
Bathymetry & ETOPO2 & $3.6 \mathrm{~km}(2 \mathrm{~min}$ of latitude) & none & http://www.ngdc.noaa.gov/mgg/global/etopo2.html \\
Surface currents & OSCAR & $36 \mathrm{~km}(20 \mathrm{~min}$ of latitude) & 5-day & www.oscar.noaa.gov
\end{tabular}

Abbreviations: CDOM, color-dissolved organic matter; CHL, chlorophyll concentration; K490, diffused attenuation; SST, sea-surface temperature. 
environmental distances, while controlling for geographical distances, using Partial Mantel tests in IBD v3.16. Environmental distances were calculated as the pairwise difference in mean chlorophyll, dissolved matter, turbidity and temperature between sites. Rejection of the null hypothesis of a negative or flat slope for the correlation between genetic and environmental distance (while controlling for the effect of geographical distance) could be used as evidence of IBED.

\section{Results}

\section{Genetic diversity}

The mtDNA sequences were partitioned into 17 haplotypes, which form a spatially structured network with three main clusters in both the Median Joining and Statistical Parsimony networks; only the former is shown (Figure 1). In particular, all 10 haplotypes found in Oman are private for that geographic area, and 9 of those form a visible cluster within the network. Haplotype 14, composed only of samples from Oman, appears approximately equally distant from the Oman cluster as it does from the other cluster in the network. The third cluster displays the Tanzania haplotypes, which are all private for that sampling area, as well as the Mozambique and South Africa haplotypes. Two Madagascar samples (collapsed into haplotype 7) are shown in the same network for comparative purposes. The Oman population $(N=58)$ displays the highest genetic diversity indices overall, whereas the Tanzania samples $(N=11)$ show the lowest indices, and Mozambique $(N=5)$ and South Africa $(N=20)$ show intermediate genetic diversity values (Table 2 ).

\section{Population structure}

The $\chi^{2}$ global test of haplotype frequencies between populations was statistically significant $\left(\chi^{2}=211.5\right.$; $\mathrm{df}=45 ; P<0.001)$. All pairwise comparisons except for South Africa vs Mozambique were statistically highly significant for both fixation indices $F_{\mathrm{ST}}$ and $\Phi_{\mathrm{ST}}$ and for the Exact test (Table 3). The MDIV-derived symmetric migration rates were highest between South Africa and
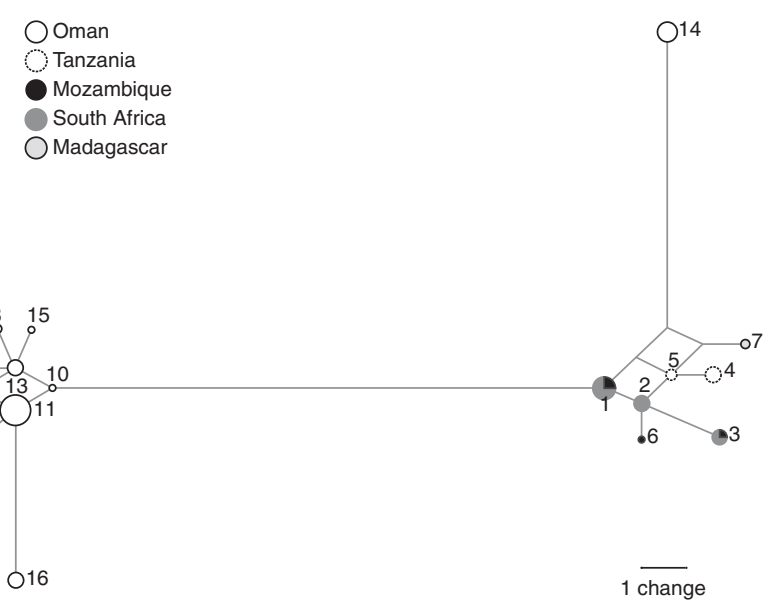

Figure 1 Median-joining network displaying the genetic relationships between all haplotypes (identified with a unique number). Haplotype colors denote their geographic location, and haplotype sizes are proportional to their frequencies.
Mozambique and smallest between Mozambique and Tanzania, with the Tanzania-Oman comparison showing intermediate rates. Interestingly, the estimated divergence times were not inversely related to the migration rates: Tanzania-Oman showed the largest time since divergence, despite having an intermediate migration rate (Table 4). MIGRATE detected asymmetric migration rates; the only comparison with a non-negligible southbound migration rate was that between Mozambique and South Africa, whereas there was no detectable southbound migration rate between Oman and Tanzania, or between Tanzania and Mozambique. The largest northbound migration rates were observed between South Africa and Mozambique (similar in absolute value to their southbound migration rates), followed by Mozambique-Tanzania, and Tanzania-Oman (Table 4).

\section{Environmental analyses}

The bathymetric image indicates a relatively narrow $(8-25 \mathrm{~km})$ continental shelf along the east coast of South Africa, and from the northeast coast of Mozambique to the Gulf of Aden. The shelf is also relatively narrow along the southwestern coast of Oman. The southwestern and southern-facing coast of South Africa (most of the coasts in Mozambique) and south coast of Oman have a wider continental shelf extending beyond $100 \mathrm{~km}$ (Figure 2).

Surface-current maps clearly show the characteristic circulation regimes described in the methods section, which generate a regional partition between both coastal provinces (Figure 3). Particularly, the January and February images show the influence of the Northeastern Monsoon in generating westbound currents immediately north of the Equator, causing a mainly southbound coastal flow. The July and August images show the influence of the Southwestern Monsoon, generating northeast-bound currents in the entire region and along the coast above the Equator. The April-May and October-November images display transition conditions between the monsoon seasons. The flow of the Mozambique Channel is largely undisturbed throughout the year.

The ocean color properties show some regional structure to the environmental variables gathered (Figure 4). Chlorophyll and turbidity are similarly structured in the region, with higher values along the southern-facing coasts of South Africa and Mozambique and most of the coast of Oman, and noticeably lower values along the coast of Tanzania. Dissolved matter shows somewhat analogous patterns, although the area with highest concentration is along the central coast of Mozambique, where the Zambezi river flows into the

Table 2 Genetic diversity indices

\begin{tabular}{lrrlll}
\hline & $\mathrm{N}$ & $\mathrm{H}$ & $\mathrm{H}_{\mathrm{d}}$ & \multicolumn{1}{c}{$\mathrm{k}$} & $\pi$ \\
\hline South Africa & 20 & 3 & 0.647 & 1.058 & 0.002 \\
Mozambique & 5 & 3 & 0.7 & 1.8 & 0.004 \\
Tanzania & 11 & 2 & 0.436 & 0.436 & 0.001 \\
Oman & 58 & 10 & 0.787 & 7.293 & 0.016 \\
\hline
\end{tabular}

Abbreviations: $\pi$, nucleotide diversity; $H$, number of haplotypes; $H_{d}$, haplotype diversity; $k$, mean number of pairwise differences among sequences; $N$, number of samples. 
Table 3 Pairwise genetic distances between sampling locations (putative populations)

\begin{tabular}{lcccc}
\hline$F_{S T} / \Phi_{S T}$ & South Africa & Mozambique & Tanzania & Oman \\
\hline South Africa & & $0(0.691) 0.128$ & $0.671(0) 0$ & $0.629(0) 0$ \\
Mozambique & $0.044(0.355) 0.131$ & $0.466(0.001) 0.001$ & $0.696(0.001) 0$ & $0.567(0.001) 0$ \\
Tanzania & $0.441(0) 0$ & $0.241(0.001) 0$ & $0.338(0) 0$ & $0.645(0) 0$ \\
Oman & $0.272(0) 0$ & 0 & \\
\hline
\end{tabular}

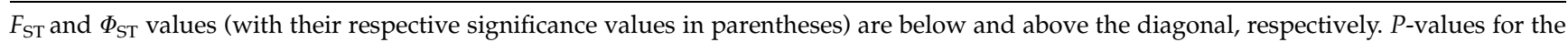
Exact test are in italics.

Table 4 Symmetric and asymmetric migration rates, time since divergence and $\theta$

\begin{tabular}{|c|c|c|c|c|c|c|c|c|c|}
\hline \multirow[t]{2}{*}{ Comparisons } & \multicolumn{3}{|c|}{ Symmetric } & \multicolumn{3}{|c|}{ South-North } & \multicolumn{3}{|c|}{ North-South } \\
\hline & $\mathrm{M}=2 \mathrm{~N}_{e} \mathrm{~m}$ (s.d.) & $\mathrm{T}=\mathrm{t} / 2 \mathrm{~N}_{e}($ s.d. $)$ & $\theta=4 \mathrm{~N}_{e} \mu$ (s.d.) & $\mathrm{M}=\mathrm{m} \mu^{-1}$ & $\theta=2 \mathrm{~N}_{e} \mu$ & $2 \mathrm{~N}_{e} \mathrm{~m}$ & $\mathrm{M}=\mathrm{m} \mu^{-1}$ & $\theta=2 \mathrm{~N}_{e} \mu$ & $2 \mathrm{~N}_{e} \mathrm{~m}$ \\
\hline South Africa-Mozambique & $8.634(7.732)$ & $0.931(0.018)$ & $0.539(0.018)$ & 790 & 0.002 & 1.58 & 718 & 0.0022 & 1.5796 \\
\hline Mozambique-Tanzania & $0.016(0.007)$ & $1.920(0.223)$ & $0.871(0.051)$ & 190 & 0.0022 & 0.418 & 0 & 0.002 & 0 \\
\hline Tanzania-Oman & $0.068(0.006)$ & $5.445(0.494)$ & $2.565(0.070)$ & 60 & 0.0027 & 0.162 & 0 & 0.0022 & 0 \\
\hline
\end{tabular}

The symmetric comparisons, performed with MDIV, show migration rate $(M)$, time since divergence $(T)$ and $\theta$ values, with their corresponding standard deviation from averaging 10 runs for each parameter. The South-North and North-South comparisons, performed with MIGRATE, show asymmetric migration rates $\left(\mathrm{m} \mu^{-1}\right.$ and $\left.2 N_{\mathrm{e}} m\right)$ and $\theta$.

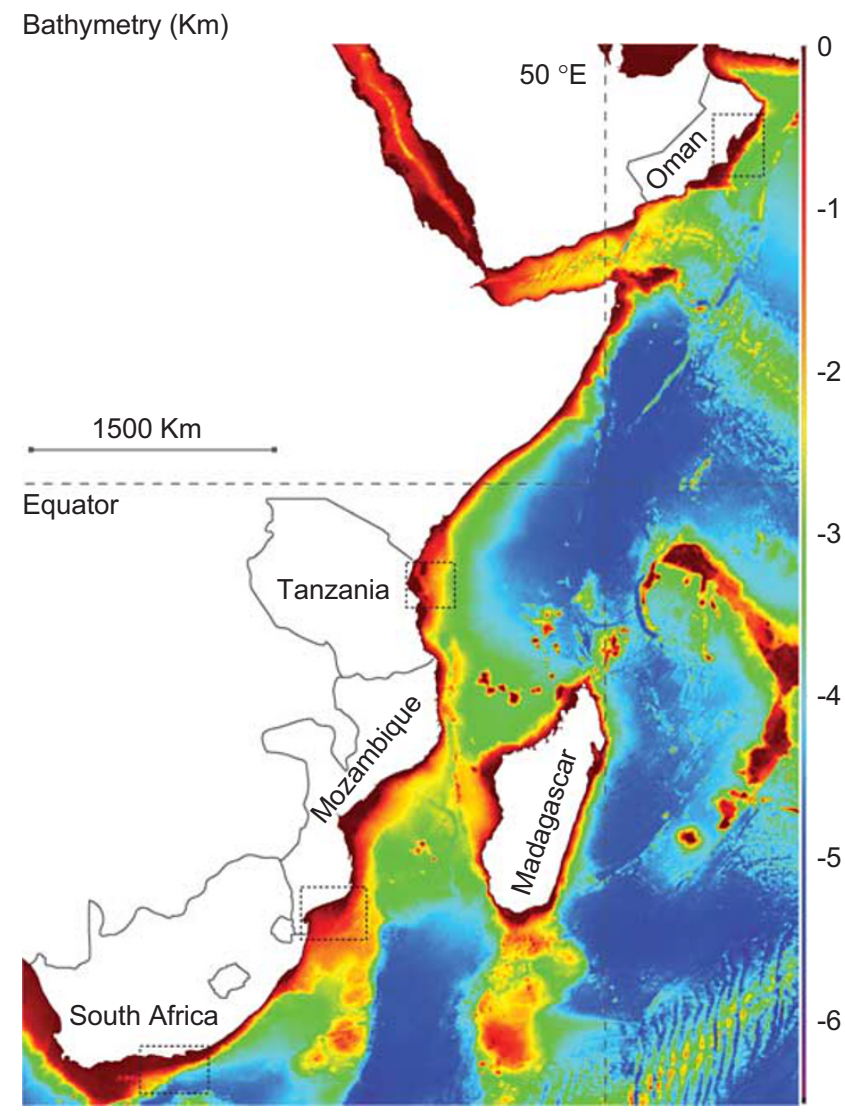

Figure 2 Regional bathymetry map displaying the countries where dolphin samples were collected, and the approximate location and size of the polygons for environmental data collection.

Indian Ocean, followed by Oman, South Africa and Tanzania. The highest variability in chlorophyll and dissolved matter is located along the South African coast, the southern-facing coasts of Mozambique and the coasts of Oman, with Tanzania displaying very small varia- bility. Variability in turbidity conditions is spatially concentrated along the coasts of South Africa and Oman. Mean surface temperature displays a latitudinal gradient with higher temperature values at lower latitudes and vice versa. The only obvious exception to this gradient is the relatively lower temperature along the coasts of South Africa. Variability in temperature conditions is relatively higher in southwestern South Africa, and along the east-facing coast of Mozambique (Figure 4).

Mean values of chlorophyll, dissolved matter, turbidity and temperature are significantly different in all comparisons between contiguous polygons representing the sampling areas (two-sided $P_{\text {(t-test) }}<0.001$ in all cases, Table 5). The climatologies constructed for the four sampling locations show notable differences between them (Figure 5). Besides the phase shift in conditions between the Northern and Southern Hemisphere, the most obvious difference between Oman and the locations in the Southern Hemisphere is caused by the seasonal monsoon: when comparing chlorophyll, dissolved matter and turbidity (Figure 5), Oman shows a peak between June and November, driven by the upwelling fields rich in nutrients that allow for high productivity, resulting in high chlorophyll and turbid water. This large change in conditions between Oman and the other locations is accompanied by a very significant quantitative effect; Oman shows values that are between 5- and 10-fold higher than the values in the other locations. When comparing the Southern Hemisphere locations, chlorophyll and turbidity are consistently higher throughout the year in South Africa, followed by Mozambique and Tanzania. Dissolved matter shows almost the same behavior, except for a reversal between South Africa and Mozambique between mid-August and mid-October. The temperature climatologies (Figure 5) display the latitudinal effect seen in the regional satellite images with a significant decrease in temperature for Oman during the Southwestern Monsoon, between July and November, caused by the upwelling of deep water masses. 

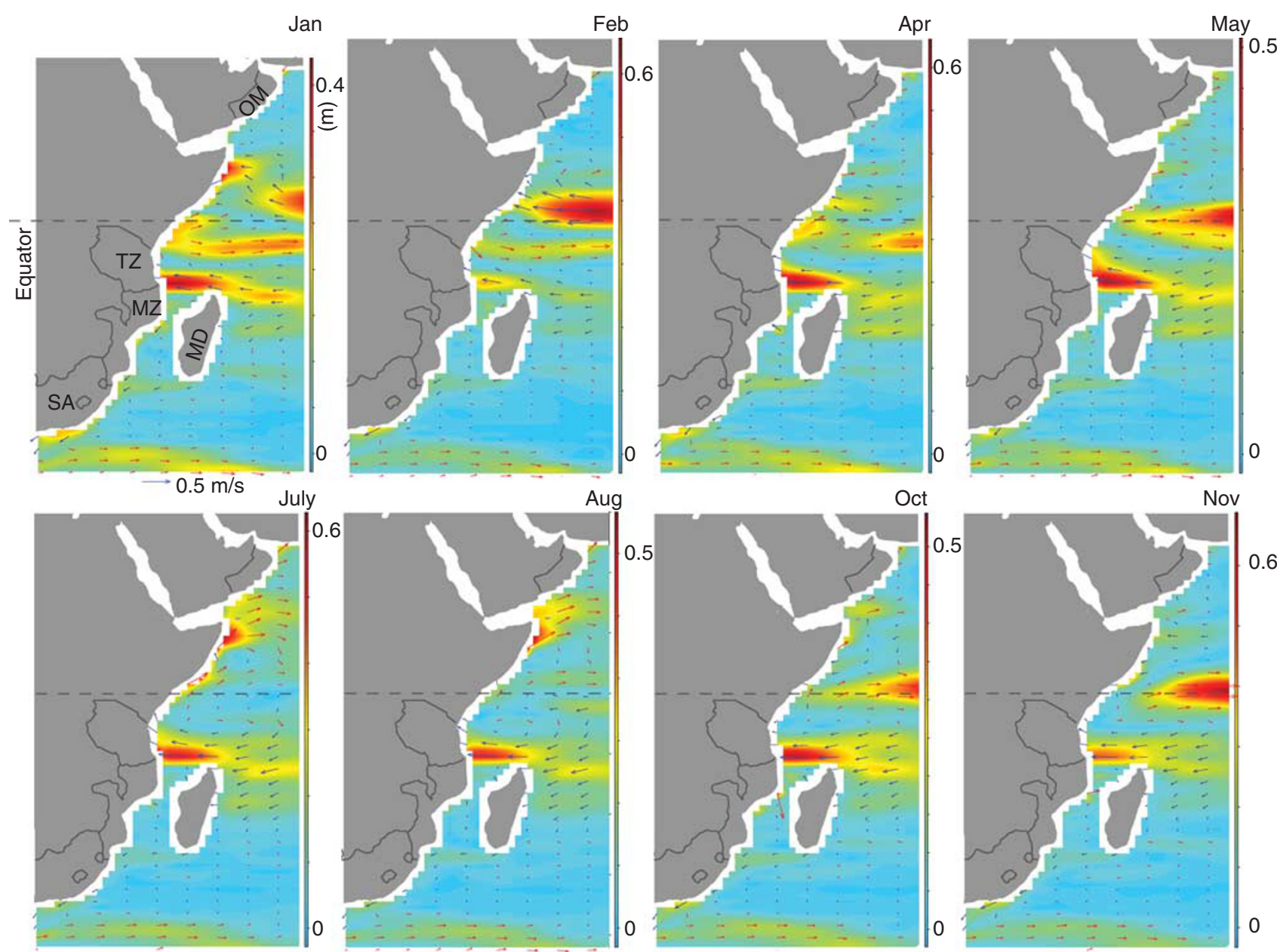

Figure 3 Regional surface current maps displaying the main differences between the Northeast Monsoon (Jan-Feb) and the Southwest Monsoon (July-Aug), and showing the transition months for comparison. Current vectors (westbound in blue, eastbound in red) are shown over a sea-surface height layer, with warmer colors corresponding to higher seas and the corresponding scales along the $Y$ axis. Country names are abbreviated (Mozambique $=\mathrm{MZ}$, Oman $=\mathrm{OM}$, South Africa $=\mathrm{SA}$ and Tanzania $=\mathrm{TZ}$ ).

\section{Genetic and environmental patterns of structure}

The bathymetry, sea current and ocean color images display notable heterogeneity in the region, clear even between contiguous sampling areas. The paired $t$-test for differences in mean values between adjacent areas confirms this. The climatologies also show quantitative differences between all the sampling regions, including measurable differences between contiguous sites. The chlorophyll, turbidity and surface temperature climatologies show a complete lack of overlap between most sampling areas, the Oman temperature series being the exception. However, as all series in Oman are temporally out of phase with those in the Southern Hemisphere, this apparent overlap lacks biological or environmental significance. A significant case of overlap occurs between South Africa and Mozambique for dissolved matter, in which the entire series' standard errors overlap.

The genetic data show highly significant differences between all adjacent populations, excepting South Africa and Mozambique (which is the only comparison that exhibited some significant environmental overlap). Therefore, all contiguous putative populations displaying significant genetic structure occur in areas that are environmentally distinguishable, and vice versa.
The Mantel tests assessing correlations between the $F_{\mathrm{ST}}$ and $\Phi_{\mathrm{ST}}$ genetic distances and the geographical distances between sampling areas were nonsignificant $(P>0.05)$ (Table 6). All correlations between $F_{\mathrm{ST}}$ and $\Phi_{\mathrm{ST}}$ genetic distances and each of the environmental distances between localities showed flat slopes and very low regression coefficients. The partial Mantel tests were nonsignificant for all tested relationships $(P>0.05)$ (Table 6).

\section{Discussion}

Our study shows a spatial overlap between the genetic structure of humpback dolphin populations and the environmental heterogeneity in their sampling areas in the Western Indian Ocean. The observed lack of correlations between genetic, geographical and environmental distances is suggestive of a scenario in which the mere existence of environmental breaks is sufficient to influence gene-flow patterns, whereas the relative magnitude of said breaks is of secondary importance.

\section{Population structure}

Our different genetic analyses show largely concordant patterns of spatial structure. The haplotype network 

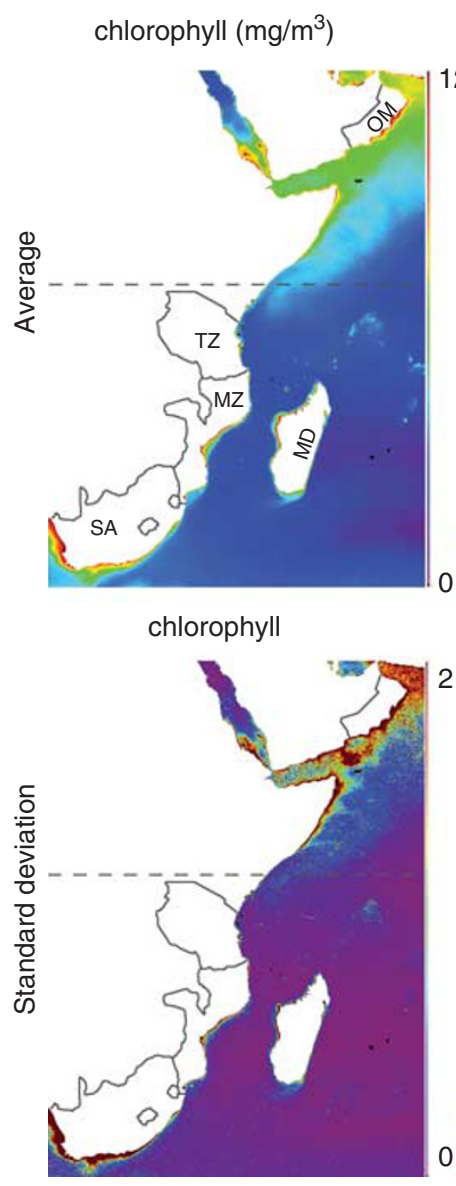

dissolved matter (unitless)

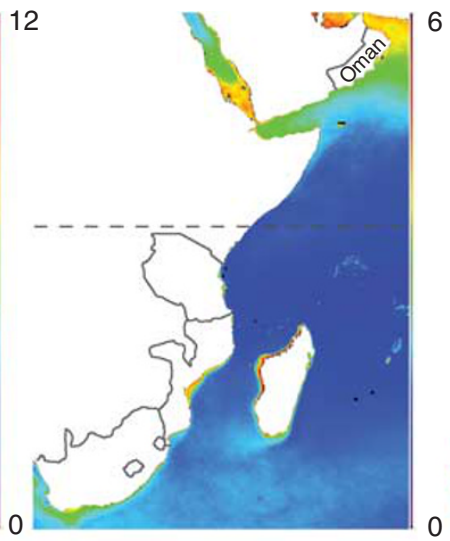

dissolved matter

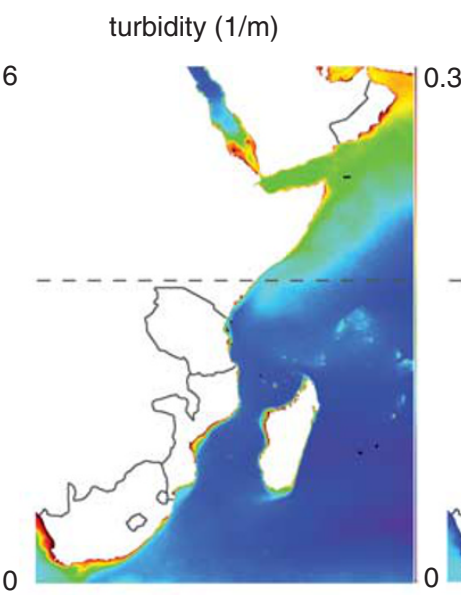

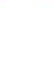
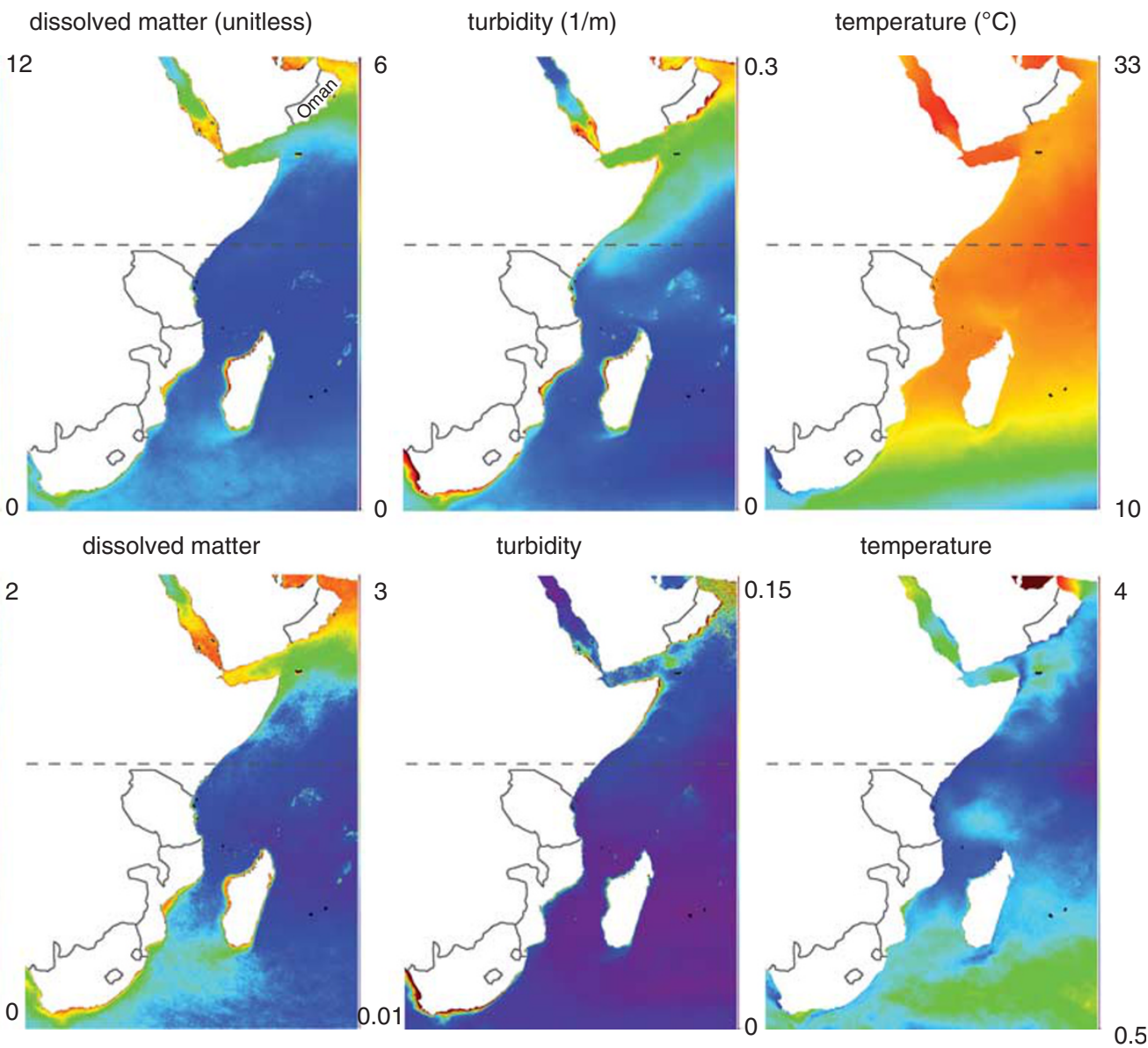

4

Figure 4 Regional ocean color maps displaying the spatial distribution of average (top row) and standard deviation (bottom row) of all measured parameters. Warmer colors correspond to higher values in all maps, and the corresponding scales are shown in the $Y$ axis. Country names are abbreviated (Mozambique $=\mathrm{MZ}$, Oman $=\mathrm{OM}$, South Africa $=\mathrm{SA}$ and Tanzania $=\mathrm{TZ}$ ).

Table 5 Comparisons of oceanographic data between contiguous population areas

\begin{tabular}{cccc}
\hline & $\begin{array}{c}\text { Oman- } \\
\text { Tanzania }\end{array}$ & $\begin{array}{c}\text { Tanzania- } \\
\text { Mozambique }\end{array}$ & $\begin{array}{c}\text { Mozambique- } \\
\text { South Africa }\end{array}$ \\
\hline CHL & & & \\
$p$ & 0.0001 & 0.0001 & 0.0001 \\
$t$ & 8.1319 & 13.779 & 17.8495 \\
df & 137 & 142 & 142 \\
CDOM & & & \\
$p$ & 0.0001 & 0.0001 & 0.0001 \\
$t$ & 17.9913 & 12.1557 & 15.539 \\
df & 132 & 142 & \\
K490 & & & 0.0001 \\
$p$ & 0.0001 & 0.0001 & 18.2743 \\
$t$ & 6.8722 & 14.0631 & 142 \\
df & 137 & 142 & 0.0001 \\
SST & & & 27.6741 \\
$p$ & 0.0001 & 0.0001 & 91 \\
$t$ & 5.7048 & 25.5206 & 91 \\
df & 91 & 91 & \\
\hline
\end{tabular}

Abbreviations: CDOM, color-dissolved organic matter; $\mathrm{CHL}$ chlorophyll concentration; df, degrees of freedom; K490, turbidity; $p, P$-value; SST, sea-surface temperature; $t$, statistic.

Summary results of the paired $t$-test to compare average values of CHL, CDOM, K490 and SST between contiguous sampling areas. The $t$-test $p, t$ and $\mathrm{df}$ are shown for each of the 12 tests. indicates spatial structure primarily responding to sample origin, with putative populations in Oman and Tanzania having only private haplotypes, and those in South Africa and Mozambique sharing haplotypes. The position of haplotype 14 is interesting as these samples were collected in Oman and yet show a closer relationship with the African samples. The highest genetic diversity and deeper divergence of the Omani population (divergence time $\mathrm{OM}-\mathrm{TZ}>\mathrm{TZ}-\mathrm{MZ}>\mathrm{MZ}-\mathrm{SA}$ ) suggest that this population could have originated the African ones. Moreover, the progression from longer to shorter divergence times is indicative of the sequence of colonization events that led to the occurrence of humpback dolphins from the Arabian Sea to the Western Indian Ocean and Southwestern Indian Ocean. Although the asymmetry of migration rates derived with MIGRATE indicates virtually no contemporary southbound migration between Oman-Tanzania and Tanzania-Mozambique, different paleoclimatic conditions during the Eocene and Oligocene (56-23 Myr ago) (Ali and Huber, 2010) may have allowed historical southbound migration events.

The highly significant fixation indices, both $F_{\mathrm{ST}}$ and $\Phi_{\mathrm{ST}}$, statistically show the strong population structure hinted at previously. Despite the strong and statistically significant differentiation between most population pairwise comparisons, it is the biological significance of 
a

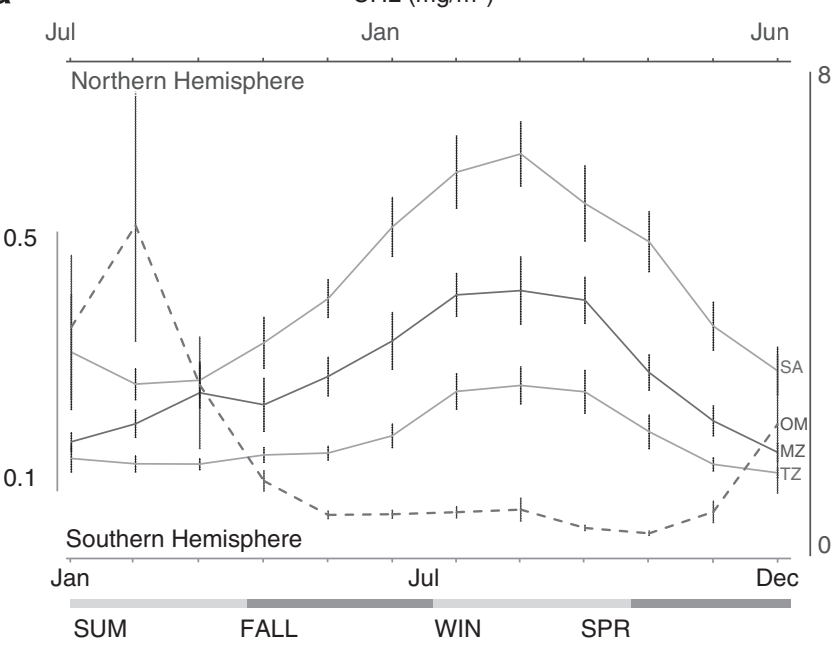

C

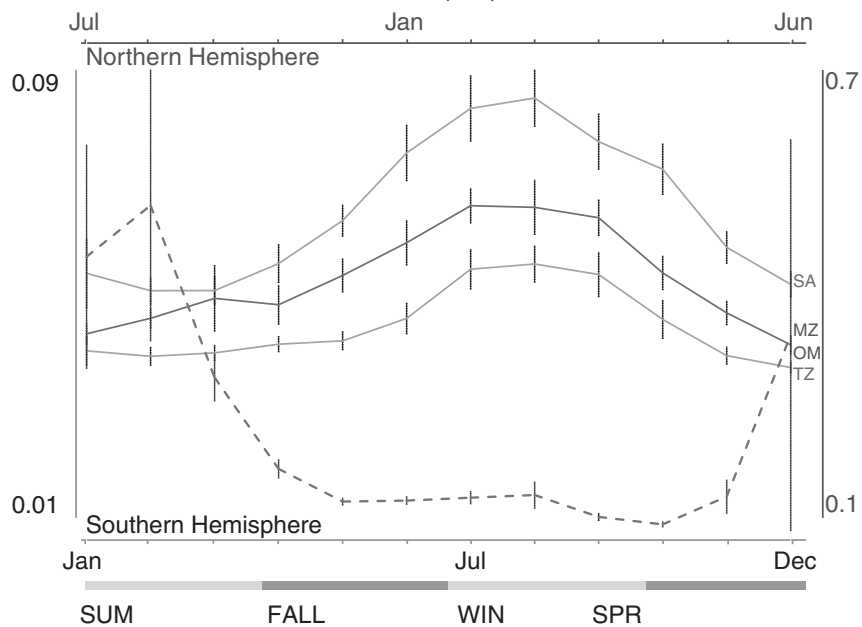

b

Jul Jan J. Jun

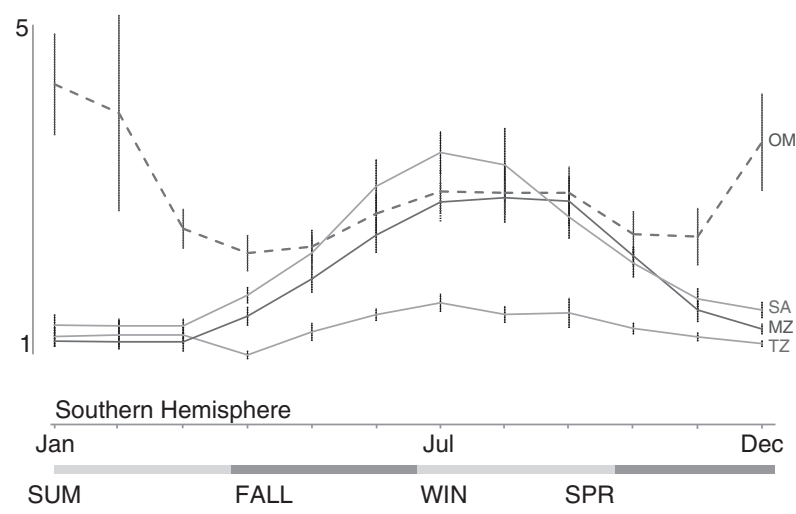

d

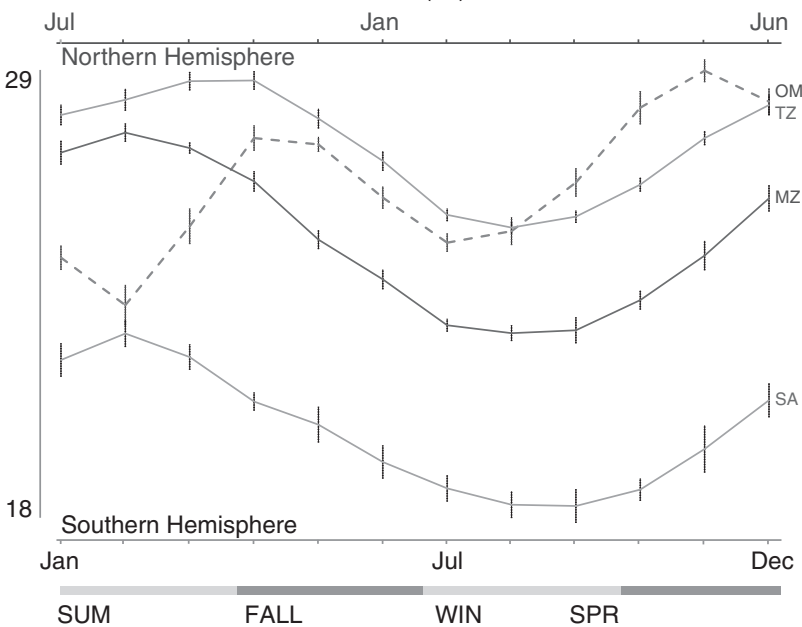

Figure 5 Climatologies at the four sampling areas. The geographic location of each series is identified by the country acronym used in Figures 3 and 4. Northern and Southern Hemisphere climatologies were aligned along the climatologic season axis at the bottom, which results in the Oman climatology to be temporally out of phase with the areas in the Southern Hemisphere. The Oman climatology is therefore displayed in red (dashed line) with its corresponding temporal axis at the top, and its $Y$ axis on the right. (a) Chlorophyll climatologies; (b) Dissolved matter climatologies; (c) Turbidity climatologies; (d) Surface temperature climatologies. A full color version of this figure is available at the Heredity journal online.

these comparisons that is of most interest (Waples and Gaggiotti, 2006). Because humpback dolphins are coastal animals, they most likely move between neighboring sampling areas in a stepwise fashion. Therefore, genetic distances between contiguous populations have the greatest biological relevance. In this context, the magnitude of the genetic structure observed between populations in Oman and Tanzania $\left(F_{\mathrm{ST}} \sim 0.34, \Phi_{\mathrm{ST}} \sim 0.64\right)$, or those in Tanzania and Mozambique $\left(F_{\mathrm{ST}} \sim 0.46\right.$, $\left.\Phi_{\mathrm{ST}} \sim 0.69\right)$, is statistically and biologically meaningful and much higher, for example, than that of neighboring populations of other small cetaceans in coastal South America (Rosa et al., 2005; Mendez et al., 2008, 2010). The combined genetic evidence from the fixation indices, migration rates and divergence times suggests that although the Oman and Tanzania populations diverged before all other populations, they are currently not the most isolated. The Tanzania and Mozambique populations are genetically more differentiated than those in Oman and Tanzania (Table 3), despite their more recent divergence. This points to agents other than divergence time contributing to the isolation of humpback dolphin populations. The evidence of asymmetric migration supports this idea and suggests that environmental heterogeneity could be at least partially responsible for genetic patterns.

\section{Environmental data}

We provide explicit evidence supporting a significant overlap of the genetic and environmental data; genetic patterns observed here could be explained, at least in part, by the oceanographic features and discontinuities in the study area.

Surface currents are known to influence and sometimes drive movement patterns in mobile marine species. For instance, currents have a strong influence on the genetic composition of green turtle (Chelonia mydas) foraging aggregations in the Atlantic Ocean (Bass et al., 2006) and the population structure of loggerhead turtles (Caretta caretta) in the Mediterranean (Carreras et al., 
Table 6 Summary results for the IBD and IBED tests

\begin{tabular}{lccccccc}
\hline Variables & \multicolumn{3}{c}{$\mathrm{F}_{S T}$} & & \multicolumn{3}{c}{$\Phi_{S T}$} \\
\cline { 2 - 4 } \cline { 6 - 7 } & $\mathrm{p}(\mathrm{r} \leqslant 0)$ & $\mathrm{r}$ & $\mathrm{R}^{2}$ & & $\mathrm{p}(\mathrm{r} \leqslant 0)$ & $\mathrm{r}$ & $\mathrm{R}^{2}$ \\
\hline Km & 0.536 & 0 & 0.001 & & 0.542 & 0 & 0.005 \\
CHL & 0.957 & 0 & 0.001 & & 0.96 & 0 & 0.005 \\
CDOM & 0.999 & 0 & 0.001 & & 0.999 & 0 & 0.005 \\
K490 & 0.956 & 0 & 0.001 & & 0.958 & 0 & 0.006 \\
SST & 0.498 & 0 & 0.001 & & 0.292 & 0 & 0.006 \\
CHL $(-K m)$ & 0.957 & & & 0.96 & & \\
CDOM $(-K m)$ & 0.959 & & & 0.999 & & \\
K490 (-Km) & 0.956 & & & 0.958 & & \\
SST $(-K m)$ & 0.458 & & & 0.373 & & \\
\hline
\end{tabular}

Abbreviations: CDOM, color-dissolved organic matter; $\mathrm{CHL}$ chlorophyll concentration; IBD, isolation by distance; IBED, isolation by environmental distance; $\mathrm{Km}$, pairwise geographical distance; K490, turbidity; $r$, slope values; $R^{2}$, correlation coefficients; SST, sea-surface temperature.

The significance $(p(r \leqslant 0)), r$ and $R^{2}$ of the correlations between genetic $\left(F_{\mathrm{ST}}\right.$ and $\left.\Phi_{\mathrm{ST}}\right)$, geographical $(\mathrm{Km})$ and environmental $(\mathrm{CHL}$, CDOM, K490, SST) distances are presented. The slope between $F_{\mathrm{ST}}$ and $\mathrm{Km}$ is expressed as $F_{\mathrm{ST}} 100 \mathrm{~km}^{-1}$. The last four rows $(-\mathrm{Km})$ assess the significance of the correlations between each environmental variable, while controlling for geographical distance, through partial Mantel tests.

2006). More generally, currents can positively impact both drifting and actively swimming animals by connecting patches of good habitat in a heterogeneous habitat matrix (Drew and Eggleston, 2006). In our study area, the permanent splitting of the South Equatorial Current into northbound and southbound coastal flows as it meets the African continent at approximately $10^{\circ} \mathrm{S}$, at current speeds higher than $0.5 \mathrm{~m} \mathrm{~s}^{-1}\left(1.8 \mathrm{~km} \mathrm{~h}^{-1}\right)$, would cause an important environmental heterogeneity between habitats in Tanzania and Mozambique. The strong population structure (and a small gene-flow rate) between both populations suggests that such an environmental break could be influencing dispersal in this species. Seasonally, with the start of the southwestern monsoon, the northbound flow continues to the Arabian Peninsula and reaches Oman. These seasonal northbound currents reach speeds of around $0.5 \mathrm{~ms}^{-1}$ and appear to be much stronger than the predominantly southbound currents during the rest of the year (Lutjeharms et al., 2000; Longhurst, 2006). The relative importance of northbound/southbound currents could explain the virtual lack of southbound migration, but some northbound migration, between populations north of the Mozambique Channel. Our assumption is that high current speeds $\left(0.5 \mathrm{~m} \mathrm{~s}^{-1}\right)$ would exert greater influence on active swimmers than low current speeds, especially when considering large spatial distances. This would mean that currents could enhance gene flow northbound only, during the southwestern monsoon season, and not be of much influence southbound during the rest of the year. In the Mozambique Channel, the revolving surface current patterns (with coastal currents and countercurrents) are largely unaffected by the monsoons. Between Mozambique and South Africa, the lack of current meandering or pulses suggests a weak effect of currents, with some northward movement related to localized gyres near shore (Lutjeharms, 2006). In the context of our results, we would suggest that the virtual symmetry of the gene flow between Mozambique and South Africa's populations, and the lack of genetic structure between them, could be explained by their spatial proximity coupled with a lack of strong, or predominantly unidirectional, current patterns in the eastern coast of Africa in the Mozambique Channel.

The heterogeneity of the CHL, CDOM, K490 and seasurface temperature data, hinted at in the regional environmental maps and reinforced statistically in all comparisons between adjacent sampling areas, points to conspicuous habitat differences between the sampling areas. The climatology data are especially relevant as they account for the natural seasonality of the measured variables, which is obscured in the average comparisons. Interestingly, the only instance of non-differentiation and the closest similarities (CHL) of the climatologic data between adjacent sampling areas is that between Mozambique and South Africa. When this evidence is coupled with the findings of no genetic structure (and highest migration rates) only between these two populations, the concordant patterns suggest an influence of environmental variables to population structure. Recent analyses in Franciscana dolphins in the Western South Atlantic (Mendez et al., 2010) and pilot whales in the North Atlantic (Fullard et al., 2000) show concordant spatial patterns of genetic variation and oceanographic breaks (including variables, such as CHL, K490 and surface temperature), and suggest that cetacean dispersal could be generally affected by environmental agents.

Nosil et al. $(2008,2009)$ coined the term 'isolation by adaptation' to refer to strong genetic differentiation mainly produced by adaptation to local environmental or ecological features. The footprints of these adaptive forces could even be observed in neutral markers, as they could be linked to non-neutral ones, or because local adaptation could reduce gene flow. The ecological patterns uncovered by the environmental and genetic data could be explained by important mechanisms related to local adaptation within marine systems. All satellite-derived variables assessed in this study (CHL, CDOM, K490 and sea-surface temperature) are related to ocean productivity (Behrenfeld and Falkowski, 1997), and the latter is often associated with fish biomass (Longhurst, 2006). For instance, the highest chlorophyll, dissolved matter and turbidity values in Oman correspond largely to the occurrence of upwelling events in the area, generated by the southwestern Monsoon. Colder and productive water masses, such as those brought to the surface during upwelling events, are typically also rich in fish biomass (Longhurst, 2006). Strong influences of productivity on species' habitat preference patterns would be expected to be reflected in their dispersal patterns and consequently on their genetic structure. Coincidentally, dispersal of mobile marine species has been documented to be influenced by foraging activities related to differential habitat use (Bass et al., 2006; Parra, 2006). Moreover, foraging specializations have been shown to influence population structure patterns in common bottlenose dolphins (Tursiops truncatus) and Indo-Pacific bottlenose dolphins (Tursiops aduncus) in Australia (Chilvers and Corkeron, 2001; Chilvers et al., 2003). Humpback dolphins have been observed feeding on productive areas (that is, reefs, estuaries, mixing areas), and their movement patterns are significantly influenced by the seasonal presence and abundance of prey species (Karczmarski et al., 1999a, 
1999b; Atkins et al., 2004; Guissamulo and Cockcroft, 2004; Parsons, 2004). Therefore, we suggest that the differences in the environmental features between sampling areas point to differences in productivity, and that such heterogeneity likely influences humpback dolphin distribution and population structure patterns.

\section{Environmental and genetic distances}

Our combined data set does not show patterns of IBD or IBED in the study area. Lack of IBD is not uncommon among cetaceans, or other mobile species, and has been attributed to a negligible influence of geography in the presence of other factors, such as behavioral constraints (Hoelzel, 1998) or environmental discontinuities (Mendez et al., 2010). The lack of IBED despite strong and seemingly overlapping genetic and environmental breaks suggests that these breaks influence the genetic structure of humpback dolphin populations in a nonlinear or proportional manner.

The presence of overlapping genetic and environmental breaks but no IBED could be explained by three alternative scenarios. First, humpback dolphin dispersal may not be influenced by the variations in the magnitude of environmental differences we were able to measure here. Rather, it would be influenced by the fact that these differences are biologically significant (that is, breaks). This would assume a scenario of environmental breaks driving genetic breaks in natural populations (Nosil et al., 2009), with the magnitude of the breaks being of secondary importance to their biological significance. Second, the magnitude of the environmental differences we see could be above the physiological threshold that limits the capability of these animals to assess the environment, and therefore the relative differences between sampling areas loses relevance above this threshold. Testing this hypothesis would require knowledge of the physiological sensitivity of cetaceans to varying environmental conditions of the kind we see in their natural habitats. A third hypothesis could be that strong female phylopatry (Greenwood, 1980) would be mainly responsible for the observed mtDNA genetic patterns, and that the samples representing these putative populations are simply contained in areas that are environmentally different. Under this third scenario, the lack of genetic differentiation between dolphins off Mozambique and South Africa, and the smaller environmental differences seen between these areas (as compared to any other in our study), would have to be considered a quantitative coincidence with no biological significance. Assessing gender-biased dispersal could shed light to this third scenario, as follows: if, within the natural limits to the species' dispersal, males showed broader dispersal, but genetic patterns were still bounded by the environmental discontinuities, it would still be logical to suggest that habitat differences have the potential to drive population structure.

The present assessment could provide valuable information for conservation strategies. Our data show evidence of highly significant population structure and restricted gene flow in Indo-Pacific humpback dolphins, particularly between populations in Oman, Tanzania and the grouping Mozambique-South Africa. As evaluations of population structure using genetic data have been the backbone of conservation strategies (DeSalle and Amato,
2004), we suggest that our genetic findings are a promising first step for efforts to define conservation and management units on the basis of population differentiation in this broad region in the Northern and Southern Indian Ocean. The genetic patterns are supported by regional and local oceanographic data, which underline the biological and ecological relevance of the population designations proposed. This approach is also valuable for our understanding of anthropogenic pressures on population structure. Fisheries, for example, have their own influence on fish biomass and distribution, which would be independent of environmental fluctuations (Halpern et al., 2008). Therefore, fisheries could affect cetacean population structure through similar but more direct mechanisms than those proposed here mediating the influence of environmental variables on productivity, and the relationship between productivity, fish biomass, and cetacean dispersal and population structure patterns.

It is important to note that our evidence, provided by the mtDNA, is necessarily a partial picture of the genetic population structure of humpback dolphins in the Western Indian Ocean. Although the use of mitochondrial markers provides an account of the matrilineal migration patterns, the addition of nuclear genetic markers would complement this picture with patrilineal patterns. Although a more comprehensive genetic data set incorporating nuclear markers and larger samples would enhance our analysis, we believe that the present combination of genetic and oceanographic data sets is informative to the main questions in this analysis, and further highlights the utility of our approach and its applicability to other marine mobile species.

\section{Conflict of interest}

The authors declare no conflict of interest.

\section{Acknowledgements}

We thank George Amato, Rob DeSalle, the Sackler Institute of Comparative Genomics, and the Lewis B and Dorothy Cullman Program in Molecular Systematics at $\mathrm{AMNH}$ for support in the laboratory. MM's work at the AMNH Marine Program is supported by the Golden Fund. We thank the NASA Ocean Biology and Biogeochemistry program for funding AS and MM. Part of the analytical work was carried out with the resources of the Computational Biology Service Unit from Cornell University, which is partially funded by Microsoft Corporation. We thank the Ocean Biology Processing Group (Code 614.2) at the GSFC, Greenbelt, MD 20771, for the production and distribution of the ocean color data. Funding for the genetic work was provided from grants to HCR. This is LDEO contribution \#7448. We are indebted to the Director and staff of the KwaZuluNatal Sharks Board for collection of specimens from the shark nets in South Africa. The fieldwork in Mozambique was possible thanks to the support from German Dolphin Conservation Society (Gesellschaft zur Rettung der Delphine e.V.), Natural History Museum of Eduardo Mondlane University in Maputo, Marine Mammal Research Program of Texas A\&M University at Galveston and General Research Fund (GRF) of Research Grant Council (RGC) Hong Kong. We thank the Institute of 
Marine Sciences, University of Dar es Salaam for their help with the collection of samples in Tanzania and especially Dr Narriman Jiddawi. WWF Sweden is acknowledged for their financial support while collecting the samples in Tanzania. Research was conducted and biopsies collected under research permit ZPR-82 and ZRP-98 issued by the Zanzibar Research Committee, Tanzania, and export of samples were done under CITES export permit 18320 issued by the Ministry of Natural Resources, Tanzania. Logistic support and research permits in Oman were provided by the Ministry of Regional Municipalities, Environment and Water Resources, the Oman Natural History Museum, and the Ministry of Agriculture and Fisheries. The fieldwork completed in Oman would not have been possible without the significant financial and logistic support provided by: The Ford Environmental Grants, The UK Foreign and Commonwealth Office, Shell Marketing Oman, Petroleum Development Oman, Veritas Geophysical, The Peter Scott Trust for Education and Research in Conservation, Emirates Airlines, Salalah Port Services, DHL Worldwide Express, Truck Oman, Oman Air, Muscat Pharmacy, KPMG, Han-Padron and Associates, and the Marina Bandar al Rowdah.

\section{References}

Ali JR, Huber M (2010). Mammalian biodiversity on Madagascar controlled by ocean currents. Nature 463: 653-657.

Amir OA, Berggren P, Ndaro SGM, Jiddawi NS (2005). Feeding ecology of the Indo-Pacific bottlenose dolphin (Tursiops aduncus) incidentally caught in the gillnet fisheries off Zanzibar, Tanzania. Estuar Coast Shelf Sci 63: 429-437.

Andrews K, Karczmarski L, Au W, Rickards S, Vanderlip C, Bowen B et al. (2010). Rolling stones and stable homes: social structure, habitat diversity and population genetics of the Hawaiian spinner dolphin (Stenella longirostris). Mol Ecol 19: 732-748.

Atkins S, Pillay N, Peddemors VM (2004). Spatial distribution of Indo-Pacific humpback dolphins (Sousa chinensis) at Richards Bay, South Africa: environmental influences and behavioural patterns. Aquat Mamm 30: 84-93.

Baker CS, Perry A, Bannister JL, Abernathy RB, Weinrich MT, Abernathy B et al. (1993). Abundant mitochondrial DNA variation and world-wide population structure in humpback whales. Proc Natl Acad Sci USA 90: 8239-8243.

Baldwin RM, Collins M, Van Waerebeek K, Minton G (2004). The Indo-Pacific humpback dolphin of the Arabian region: a status review. Aquat Mamm 30: 111-124.

Bandelt HJ, Forster P, Röhl A (1999). Median-joining networks for inferring intraspecific phylogenies. Mol Biol Evol 16: 37-48.

Bass AL, Epperly SP, Braun-McNeill J (2006). Green turtle (Chelonia mydas) foraging and nesting aggregations in the Caribbean and Atlantic: impact of currents and behavior on dispersal. J Hered 97: 346-354.

Beerli P, Felsenstein J (2001). Maximum likelihood estimation of a migration matrix and effective population sizes in $\mathrm{n}$ subpopulations by using a coalescent approach. Proc Natl Acad Sci USA 98: 4563-4568.

Behrenfeld MJ, Falkowski PG (1997). Photosynthetic rates derived from satellite-based chlorophyll concentration. Limnol Oceanogr 41: 1-20.

Bohonak AJ (2002). IBD (isolation by distance): a program for analyses of isolation by distance. J Hered 93: 153-154.

Carreras C, Pont S, Maffucci F, Pascual M, Barcelo A, Bentivegna $\mathrm{F}$ et al. (2006). Genetic structuring of immature loggerhead sea turtles (Caretta caretta) in the Mediterranean Sea reflects water circulation patterns. Mar Biol 149: 1269-1279.

Chilvers BL, Corkeron PJ (2001). Trawling and bottlenose dolphins' social structure. Proc $R$ Soc Lond B Biol Sci 268: 1901-1905.

Chilvers BL, Corkeron PJ, Puotinen ML (2003). Influence of trawling on the behaviour and spatial distribution of IndoPacific bottlenose dolphins (Tursiops aduncus) in Moreton Bay, Australia. Can J Zool-[Rev Canad Zool] 81: 1947-1955.

Chivers SJ, Dizon AE, Gearin PJ, Robertson KM (2002). Smallscale population structure of eastern North Pacific harbour porpoises (Phocoena phocoena) indicated by molecular genetic analyses. J Cetacean Res Manage 4: 111-122.

Clement M, Posada D, Crandall KA (2000). TCS: a computer program to estimate gene genealogies. Mol Ecol 9: 1657-1659.

Dalebout MK, Hooker SK, Christensen I (2001). Genetic diversity and population structure among northern bottlenose whales, Hyperoodon ampullatus, in the western North Atlantic Ocean. Can J Zool 79: 478-484.

Davis RW, Ortega-Ortiz JG, Ribic CA, Evans WE, Biggs DC, Ressler PH et al. (2002). Cetacean habitat in the northern oceanic Gulf of Mexico. Deep-Sea Res 49: 121-142.

DeSalle R, Amato G (2004). The expansion of conservation genetics. Nat Rev Genet 5: 702-713.

Drew CA, Eggleston DB (2006). Currents, landscape structure, and recruitment success along a passive-active dispersal gradient. Landscape Ecol 21: 917-931.

Excoffier L, Laval G, Schneider S (2005). Arlequin ver. 3.0: an integrated software package for population genetics data analysis. Evol Bioinform Online 1: 47-50.

Frere CH, Hale PT, Porter L, Cockcroft VG, Dalebout ML (2008). Phylogenetic analysis of mtDNA sequences suggests revision of humpback dolphin (Sousa spp.) taxonomy is needed. Mar Freshwater Res 59: 259-268.

Fullard K, Early G, Heide-Jorgensen M, Bloch D, Rosing-Asvid A, Amos W (2000). Population structure of long-finned pilot whales in the North Atlantic: a correlation with sea surface temperature? Mol Ecol 9: 949-958.

Gaggiotti OE, Bekkevold D, Jorgensen HBH, Foll M, Carvalho GR, Andre C et al. (2009). Disentangling the effects of evolutionary, demographic, and environmental factors influencing genetic structure of natural populations: Atlantic herring as a case study. Evolution 63: 2939-2951.

Greenwood PJ (1980). Mating systems, philopatry and dispersal in birds and mammals. Anim Behav 28: 1140-1162.

Guissamulo A, Cockcroft VG (2004). Ecology and population estimates of Indo-Pacific humpback dolphins (Sousa chinensis) in Maputo Bay, Mozambique. Aquat Mamm 30: 94-102.

Halpern BS, Walbridge S, Selkoe KA, Kappel CV, Micheli F, $\mathrm{D}^{\prime}$ Agrosa $\mathrm{C}$ et al. (2008). A global map of human impact on marine ecosystems. Science 319: 948-952.

Hoelzel AR (1998). Genetic structure of cetacean populations in sympatry, parapatry, and mixed assemblages: implications for conservation policy. J Hered 89: 451-458.

Hung SK, Jefferson TA (2004). Ranging patterns of Indo-Pacific humpback dolphins (Sousa chinensis) in the Pearl River estuary, Peoples Republic of China. Aquat Mamm 30: 159-174.

Jefferson TA, Hung SK (2004). A review of the status of the Indo-Pacific humpback dolphin (Sousa chinensis) in Chinese waters. Aquat Mamm 30: 149-158.

Jefferson TA, Karczmarski L (2001). Sousa chinensis. Mamm Species 655: 1-9.

Karczmarski L (1999). Group dynamics of humpback dolphins (Sousa chinensis) in the Algoa Bay region, South Africa. J Zool 249: 283-293.

Karczmarski L, Cockcroft VG (1999). Daylight behaviour of humpback dolphins Sousa chinensis in Algoa Bay, South Africa. Zeitschrift Fur Saugetierkunde-Int J Mamm Biol 64: 19-29.

Karczmarski L, Cockcroft VG, McLachlan A (1999a). Group size and seasonal pattern of occurrence of humpback dolphins 
Sousa chinensis in Algoa Bay, South Africa. S Afr J Mar Sci [Suid-Afrikaanse Tydskrif Vir Seewetenskap] 21: 89-97.

Karczmarski L, Cockcroft VG, McLachlan A (2000). Habitat use and preferences of Indo-Pacific humpback dolphins Sousa chinensis in Algoa Bay, South Africa. Mar Mamm Sci 16: 65-79.

Karczmarski L, Winter PED, Cockcroft VG, McLachlan A (1999b). Population analyses of Indo-Pacific humpback dolphins Sousa chinensis in Algoa Bay, Eastern Cape, South Africa. Mar Mamm Sci 15: 1115-1123.

Keith M, Peddemors VM, Bester MN, Ferguson JWH (2002). Population characteristics of Indo-Pacific humpback dolphins at Richards Bay, South Africa: implications for incidental capture in shark nets. S Afr J Wildl Res 32: 153-162.

Krützen M, Sherwin WB, Berggren P, Gales N (2004). Population structure in an inshore cetacean revealed by microsatellite and mtDNA analysis: bottlenose dolphins (Tursiops sp.) in Shark Bay, Western Australia. Mar Mamm Sci 20: 28-47.

Longhurst AR (2006). Ecological Geography of the Sea 2nd edn. Academic Press: San Diego. 560pp.

Lutjeharms JRE (2006). The Agulhas Current. Springer: Berlin; New York. Xiii, 329pp.

Lutjeharms JRE, Wedepohl PM, Meeuwis JM (2000). On the surface drift of the East Madagascar and Mozambique currents. S Afr J Sci 96: 141-147.

Mendez M, Rosenbaum HC, Bordino P (2008). Conservation genetics of the franciscana dolphin in Northern Argentina: population structure, by-catch impacts, and management implications. Conserv Genet 9: 419-435.

Mendez M, Rosenbaum HC, Subramaniam A, Yackulic C, Bordino P (2010). Isolation by environmental distance in mobile marine species: molecular ecology of franciscana dolphins at their southern range. Mol Ecol 19: 2212-2228.

Narum SR (2006). Beyond bonferroni: less conservative analyses for conservation genetics. Conserv Genet 7: 783-787.

Nei M (1987). Molecular Evolutionary Genetics. Columbia University Press: New York.

Nielsen R, Wakeley J (2001). Distinguishing migration from isolation: a Markov chain Monte Carlo approach. Genetics 158: 885-896.

Nosil P, Egan SP, Funk DJ (2008). Heterogeneous genomic differentiation between walking-stick ecotypes: 'isolation by adaptation' and multiple roles for divergent selection. Evolution 62: 316-336.

Nosil P, Funk DJ, Ortiz-Barrientos D (2009). Divergent selection and heterogeneous genomic divergence. Mol Ecol 18: 375-402.

Parra GJ (2006). Resource partitioning in sympatric delphinids: space use and habitat preferences of Australian snubfin and Indo-Pacific humpback dolphins. J Anim Ecol 75: 862-874.

Parra GJ, Corkeron PJ, Marsh H (2004). The Indo-Pacific humpback dolphin, Sousa chinensis (Osbeck, 1765), in Australian waters: a summary of current knowledge. Aquat Mamm 30: 197-206.
Parsons ECM (1998). Observations of Indo-Pacific humpbacked dolphins, Sousa chinensis, from Gao, Western India. Mar Mamm Sci 14: 166-170.

Parsons ECM (2004). The behavior and ecology of the IndoPacific humpback dolphin (Sousa chinensis). Aquat Mamm 30: 38-55.

Peddemors VM (1999). Delphinids of southern Africa: a review of their distribution, status and life history. I Cetacean Res Manag 1: 157-165.

Peddemors VM, Thompson G (1994). Beaching behaviour during shallow water feeding by humpback dolphins Sousa plumbea. Aquat Mamm 20: 65-67.

Perneger TV (1998). What's wrong with Bonferroni adjustments. BMJ 316: 1236-1238.

Reeves RR, Dalebout ML, Jefferson TA, Karczmarski L, Laidre $\mathrm{K}$, O'Corry-Crowe G et al. (2008). IUCN 2010. IUCN Red List of Threatened Species. Version 2010.1 (www.iucnredlist.org). Downloaded on 08 April 2010.

Rice D (1998). Marine Mammals of the World: Systematics and Distribution vol. special publication 4. Allen Press-The Society for Marine Mammalogy: Lawrence, KS.

Rosa S, Milinkovitch MC, Van Waerebeek K, Berck J, Oporto J, Alfaro-Shigueto J et al. (2005). Population structure of nuclear and mitochondrial DNA variation among South American Burmeister's porpoises (Phocoena spinipinnis). Conservation Genet 6: 431-443.

Rosenbaum HC, Pomilla C, Mendez M, Leslie MS, Best PB Findlay KP et al. (2009). Population structure of humpback whales from their breeding grounds in the South Atlantic and Indian Oceans. PLOS ONE 4: e7318.

Rozas J, Sánchez-DelBarrio JC, Messegyer X, Rozas R (2003). DnaSP, DNA polymorphism analyses by the coalescent and other methods. Bioinformatics 19: 2496-2497.

Stensland E, Carlen I, Sarnblad A, Bignert A, Berggren P (2006). Population size, distribution, and behavior of Indo-Pacific bottlenose (Tursiops aduncus) and humpback (Sousa chinensis) dolphins off the south coast of Zanzibar. Mar Mamm Sci 22 667-682.

Sutaria D, Jefferson TA (2004). Records of Indo-Pacific humpback dolphins (Sousa chinensis, Osbeck, 1765) along the coasts of India and Sri Lanka: an overview. Aquat Mamm 30: 125-136.

Tajima F (1983). Evolutionary relationships of DNA sequences in finite populations. Genetics 105: 437-460.

Wang JY, Hung SK, Yang SC (2004). Records of Indo-Pacific humpback dolphins, Sousa chinensis (Osbeck, 1765), from the waters of western Taiwan. Aquat Mamm 30: 189-196.

Waples RS, Gaggiotti O (2006). What is a population? An empirical evaluation of some genetic methods for identifying the number of gene pools and their degree of connectivity. Mol Ecol 15: 1419-1439.

Wright S (1943). Isolation by distance. Genetics 28: 114-138. 